\section{(6) OPEN ACCESS}

${ }^{1}$ Research and Education Centre, ASPETAR, Qatar Orthopaedic and Sports Medicine Hospital, Doha, Qatar 2Department of Physiology, Faculty of Biology and Medicine, Institute of Sports Sciences, University of Lausanne, Lausanne, Switzerland

\section{Correspondence to} Dr Olivier Girard, Research and Education Centre, ASPETAR, Qatar Orthopaedic and Sports Medicine Hospital PO Box 29222, Doha, Qatar; oliv.girard@gmail.com

Accepted 1 August 2013

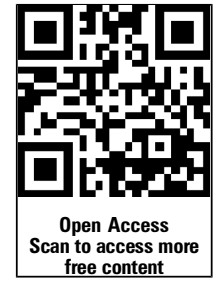

To cite: Girard 0 , Brocherie F, Millet GP. Br J Sports Med 2013;47: i121-i123.

\title{
On the use of mobile inflatable hypoxic marquees for sport-specific altitude training in team sports
}

\author{
Olivier Girard, ${ }^{1}$ Franck Brocherie, ${ }^{2}$ Grégoire P Millet ${ }^{2}$
}

\begin{abstract}
Background/aim With the evolving boundaries of sports science and greater understanding of the driving factors in the human performance physiology, one of the limiting factors has now become the technology. The growing scientific interest on the practical application of hypoxic training for intermittent activities such as team and racket sports legitimises the development of innovative technologies serving athletes in a sportspecific setting.

Methods Description of a new mobile inflatable simulated hypoxic equipment.

Results The system comprises two inflatable unitsthat is, a tunnel and a rectangular design, each with a $215 \mathrm{~m}^{3}$ volume and a hypoxic trailer generating over $3000 \mathrm{Lpm}$ of hypoxic air with $\mathrm{FiO}_{2}$ between 0.21 and 0.10 (a simulated altitude up to $5100 \mathrm{~m}$ ). The inflatable units offer a $45 \mathrm{~m}$ running lane (width $=1.8 \mathrm{~m}$ and height $=2.5 \mathrm{~m}$ ) as well as a $8 \mathrm{~m} \times 10 \mathrm{~m}$ dome tent. $\mathrm{FiO}_{2}$ is stable within a range of $0.1 \%$ in normal conditions inside the tunnel. The air supplied is very dry-typically $10-15 \%$ relative humidity.

Conclusions This mobile inflatable simulated hypoxic equipment is a promising technological advance within sport sciences. It offers an opportunity for team-sport players to train under hypoxic conditions, both for repeating sprints (tunnel configuration) or small-side games (rectangular configuration).
\end{abstract}

\section{USING SPORT-SCIENCE RESEARCH TO IMPROVE PRACTICE}

Sports-science research is concerned with providing coaches and athletes support and expertise that may improve athletic performance and/or reduce the incidence of injury. ${ }^{1}$ To achieve these goals, it is necessary to use the findings of well-designed protocols that range from 'applied research' (ie, outcome directly applied in the sporting environment) through 'basic research' (ie, mechanistic approach). However, in addition to some inherent problems of transfer (eg, conservative coaching attitudes, outdated coach education), the translation of scientific knowledge to a practical setting is generally poor, ${ }^{2}$ especially in professional sport applications.

The structure of scientific inquiry itself (ie, the way in which research is conducted) undoubtedly plays a role in the extent to which scientific knowledge is implemented in everyday practice. $^{3}$ Well-designed protocols using sport-specific conditions (eg, for football players, on natural grass with soccer boots) permit a more informative discussion on how to better customise/apply research findings in field conditions and vice versa and on how applied experiments can be used to yield a deeper understanding of inherent mechanisms.

\section{ON-FIELD HYPOXIC TRAINING}

Hypoxic/altitude training - whether it is the traditional 'live high-train high' or the more recent 'live high-train low'-is a popular ergogenic aid among competitive athletes. ${ }^{4}$ Owing to disruptions to their normal training environment and lifestyle, it is, however, not viable for all elite athletes to use chronic altitude exposure strategies.

In order to simulate the physiological effects of altitude, the technical development of new devices that either decrease the pressure of the inspired air (hypobaric chamber) or reduce the concentration of oxygen in the inspired air by diluting it with extra nitrogen or filtering out oxygen (altitude tents, hypoxicator machines) has recently become available. These devices have stimulated the development of a number of training procedures-intermittent hypoxic training ${ }^{4}$ and repeated-sprint training in hypoxia ${ }^{5}$ - to improve athletic performance, yet mostly conducted with individual (endurance) athletes tested on a cycle ergometer.

Despite the belief that altitude exposure is a promising strategy in team sports, ${ }^{4-9}$ the benefits of altitude training on performance (repeated sprint ability) and the physiological systems relevant to team-sport athletes still need to be established in more sport-specific test settings.

\section{TECHNICAL SPECIFICITIES OF THE HYPOXIC SYSTEM}

A new mobile inflatable simulated hypoxic equipment (Altitude Training Systems-High Performance Unit, Australia) was designed to ISO standards (ISO 13485:2008) exclusively for Aspetar (Qatar Orthopaedic and Sports Medicine Hospital) and showcased for the first time during the Altitude Training and Team Sports conference, held in Doha in March 2013.

\section{System specifications}

The system comprises two inflatable units-that is, a tunnel and a rectangular design (figure 1), offering each a volume of $215 \mathrm{~m}^{3}$-and a state-of-the-art hypoxic trailer $(55 \mathrm{~kW}$ screw compressor), generating over $3000 \mathrm{Lpm}$ of hypoxic air with $\mathrm{FiO}_{2}$ between 0.21 and 0.10 (a simulated altitude up to $5100 \mathrm{~m}$ ). This hypoxic system would offer team-sport athletes the ability to train in sport-specific conditions for a variety of different match-related activities and tasks. Hence, made from industrial grade polyvinyl chloride (PVC), the inflatable units offer a $45 \mathrm{~m}$ running lane (width $=1.8 \mathrm{~m}$ and height $=2.5 \mathrm{~m}$ ) to assist with sprints and running simulations, as well as an 


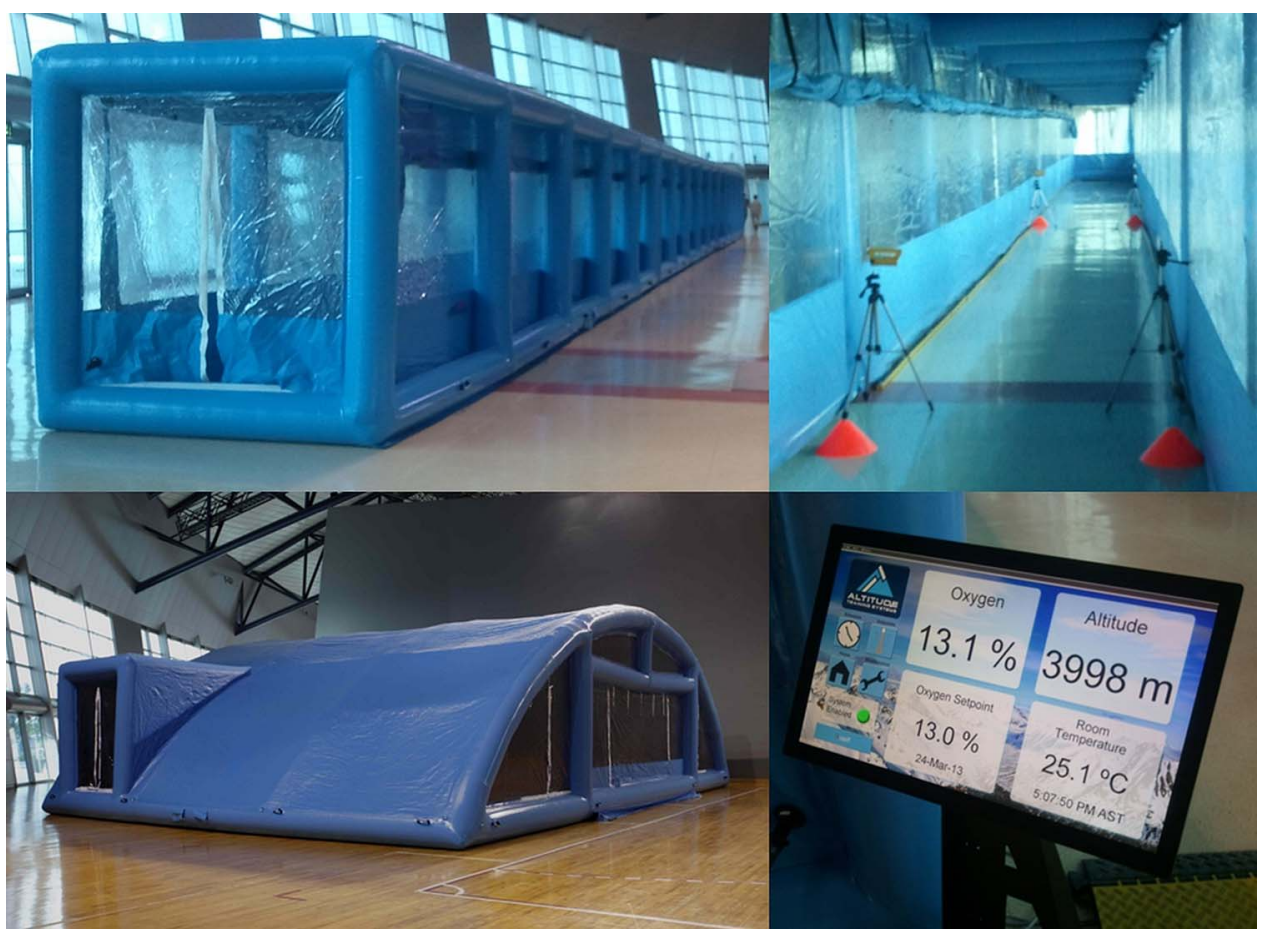

Figure 1 The mobile inflatable simulated hypoxic equipment as it was presented during the Doha conference. External (top left panel) and inside (top right panel) tunnel views are pictured along with the rectangular design (bottom left panel) and touch screen controller (bottom right panel).

$8 \mathrm{~m} \times 10 \mathrm{~m}$ dome tent which can be utilised for small-sided games and other skill-based training, for example, circuit training.

$\mathrm{FiO}_{2}$ is measured every $5 \mathrm{~s}$ by two sensors located at two points in the tunnel $(15$ and $30 \mathrm{~m})$, that is, the average of the two sensors being then displayed on the touch screen (figure 1, bottom right panel). It is stable within a range of $0.1 \%$ in normal conditions inside the tunnel. The stability is somewhat dependent on the entry and exit of athletes in the tunnel, but due to the high flow rate $(3000 \mathrm{Lpm})$ the system can compensate very quickly to remain stable at the desired level. The air supplied is very dry-typically $10-15 \%$ relative humidity. This dry air counteracts the humidity generated during the exercise, usually resulting in comfortable humidity levels without the need for dehumidification.

\section{System usability}

The inflatables are very easily inflated in just $20 \mathrm{~min}$; then, by connecting to the altitude trailer, the system can be up and running in under $2 \mathrm{~h}$. Once set up, it is possible to schedule sessions for a week by programming the target simulated altitude and the timing of the sessions. Because the time for changing $\mathrm{FiO}_{2}$ is an important parameter in an applied setting, the simulated altitude can be changed from one session to another to better adjust to the characteristics of the athletes. In the tunnel, the time for changing from sea level to a simulated altitude of $3500 \mathrm{~m}$ was measured twice and was 43 and $45 \mathrm{~min}$, respectively.

Statistics for the $\mathrm{FiO}_{2}$ (or equivalent altitude in $\mathrm{m}$ ) set point and level, temperature, $\mathrm{FiCO}_{2}$ level and line pressures over a selected time period are available. $\mathrm{FiCO}_{2}$ is measured permanently and the maximum is $5000 \mathrm{ppm}$. Safety is warranted by an alarm if $\mathrm{FiCO}_{2}$ exceeds this value. Similarly, a low oxygen warning is set to appear if the hypoxic level in the room reaches $1 \%$ below the $\mathrm{FiO}_{2}$ set point and automatic shutdown occurs in such a hazardous situation. Preliminary testing showed that up to 10 participants can perform $30 \mathrm{~m}$ repeated sprints in the tunnel with $\mathrm{FiCO}_{2}$ stabilised at $<3000$ ppm.

\section{POTENTIAL BENEFITS OF USING THE HYPOXIC SYSTEM Discovering new possibilities}

Using the mobile inflatable simulated hypoxic facilities will undoubtedly contribute to advancing our understanding of hypoxia-induced physiological adaptations by conducting relevant research in the most sport-specific ecological test setting (Bringing the Mountains to the field or even to the desert). While most of the existing altitude training methods have been developed to serve the individual athlete, testing the efficacy of an approach by combining different hypoxic methods-for example, live high-train low and high interspersed, as suggested by Millet et $a l^{4}$ or living high and training high and/or in the heat-is now possible.

By closely matching the specific needs of team sport players, the use of this equipment will open new frontiers to optimise future hypoxic training applications (eg, preacclimatisation, tapering and rehabilitation, performance maintenance, effectiveness of hypobaric versus normobaric hypoxic methods).

\section{Repeated-sprint training in hypoxia}

In one study, our research group reported that the succession of maximal efforts performed in hypoxia versus normoxia is more efficient when maximal sprints, with incomplete recoveries, are repeated until exhaustion. ${ }^{5}$ This study has highlighted the major benefits of repeated sprint training in hypoxia on glycolytic performance, skeletal muscle adaptation and ventilatory responses suggesting the putative strong benefits for team-sport performance. However, in the only two available studies that evaluated the effectiveness of repeated sprint training in hypoxia, training/testing sessions have been 
completed on a cycle ergometer in a climatic chamber. ${ }^{5} 10$ One may therefore question the validity of these findings for team-sport athletes.

Repeated sprinting on natural grass with players wearing their soccer boots is known to induce specific impairments in legspring behaviour (vertical stiffness), ${ }^{11}$ which may not occur when players are tested on cycle ergometers. Hence, the intensity of the mechanical activity that the musculoskeletal system can transiently achieve, which presumably determines the quantities of metabolic energy released and therefore the level of performance attained, differs fundamentally between the cycling-based and running-based sprint efforts. ${ }^{12}$

\section{From the laboratory to the field}

Using non-motorised instrumented treadmills allows a deeper understanding of the effects of various interventions (eg, fatigue $^{13}$ or hypoxia: Brocherie et al unpublished observations) on neuromechanical adjustments during repeated sprints. Noteworthy, however, is that treadmill and field sprint performance differs by about $20 \%,{ }^{14}$ highlighting that the lower speed reached on the treadmill may not be optimal to maximise the sprint-related training benefits.

The mobile inflatable simulated hypoxic equipment now permits limitations to be counterbalanced by using laboratorybased equipments (eg, cycle ergometer and treadmill). Additionally, to date, the potential benefits of executing smallsided games or other skill-based training under hypoxic conditions are unknown. It is unfortunate because this training drill has been proposed as an efficient alternative in football for developing aerobic capacity and some technical abilities including changes of direction or short passes. ${ }^{15} 16$ Performing smallsided games under hypoxic conditions, theoretically, has the potential to maximise expected training benefits, but further studies are required to verify this assumption.

\section{CONCLUSION}

The mobile inflatable simulated hypoxic equipment is a promising technological advance within sport sciences. Whether it is repeated sprints (tunnel configuration) or small-side games (rectangular configuration), it offers the opportunity for team-sport players to train under hypoxic conditions.

\section{What this study adds}

Mobile hypoxic inflatable marquees-directly located on the playing ground-are now available, opening new boundaries in future advancements of hypoxic training practical applications. Coaches and athletes are likely to be more accepting of sport-science research if results have direct relevance to their programmes and can be applied in a sport-specific setting.
Funding This work was supported by Aspire Zone Foundation grant number AF/C/ASP1905/11.

Competing interests None.

Provenance and peer review Not commissioned; externally peer reviewed.

Open Access This is an Open Access article distributed in accordance with the Creative Commons Attribution Non Commercial (CC BY-NC 3.0) license, which permits others to distribute, remix, adapt, build upon this work non-commercially, and license their derivative works on different terms, provided the original work is properly cited and the use is non-commercial. See: http://creativecommons.org/ licenses/by-nc/3.0/

\section{REFERENCES}

1 Bishop D, Burnett A, Farrow D, et al. Sports-science roundtable: does sports-science research influence practice? Int J Sports Physiol Perform 2006;1:161-8.

2 Crowley WF Jr. Translation of basic research into useful treatments: how often does it occur? Am J Med 2003;114:503-5.

3 Ginexi EM, Hilton TF. What's next for translation research? Eval Health Prof 2006;29:334-47.

4 Millet GP, Roels $B$, Schmitt $L$, et al. Combining hypoxic methods for peak performance. Sports Med 2010;40:1-25.

5 Faiss R, Leger B, Vesin JM, et al. Significant molecular and systemic adaptations after repeated sprint training in hypoxia. PLOS ONE 2013;8:e56522.

6 Bartsch P, Dvorak J, Saltin B. Football at high altitude. Scand J Med Sci Sports 2008; 18:iii-iv.

7 Bergeron MF, Bahr R, Bartsch P, et al. International Olympic Committee consensus statement on thermoregulatory and altitude challenges for high-level athletes. $\mathrm{Br} \mathrm{J}$ Sports Med 2012;46:770-9.

8 Lundby $C$, Millet GP, Calbet JA, et al. Does 'altitude training' increase exercise performance in elite athletes? Br J Sports Med 2012;46:792-5.

9 Billaut F, Gore CJ, Aughey RJ. Enhancing team-sport athlete performance: is altitude training relevant? Sports Med 2012;42:751-67.

10 Puype J, Van Proeyen K, Raymackers JM, et al. Sprint interval training in hypoxia stimulates glycolytic enzyme activity. Med Sci Sports Exerc 2013. In press.

11 Girard O, Racinais S, Kelly L, et al. Repeated sprinting on natural grass impairs vertical stiffness but does not alter plantar loading in soccer players. Eur J Appl Physiol 2011;111:2547-55.

12 Bundle MW, Weyand PG. Sprint exercise performance: does metabolic power matter? Exerc Sport Sci Rev 2012;40:174-82.

13 Morin JB, Samozino P, Edouard P, et al. Effect of fatigue on force production and force application technique during repeated sprints. J Biomech 2011;44:2719-23.

14 Morin JB, Sève P. Sprint running performance: comparison between treadmill and field conditions. Eur J Appl Physiol 2011;111:1695-703.

15 Hill-Haas SV, Dawson B, Impellizzeri FM, et al. Physiology of small-sided games training in football: a systematic review. Sports Med 2011;41:199-220.

16 Dellal A, Varliette C, Owen A, et al. Small-sided games versus interval training in amateur soccer players: effects on the aerobic capacity and the ability to perform intermittent exercises with changes of direction. J Strength Cond Res 2012;26:2712-20. 